\title{
Addressing Growth in Viewership Through Various Media Streams Within the ABC: A Review of Enterprise Architecture and Proposed Solutions
}

\author{
Yanli $\mathrm{Li}^{1}$ \\ ${ }^{1}$ University of Technology Sydney, Sydney, Australia \\ Correspondence: Yanli Li, University of Technology Sydney, Sydney, Australia.
}

Received: December 6, 2019

Accepted: December 24, 2019

Online Published: December 26, 2019

doi:10.20849/ajsss.v4i4.694

URL: https://doi.org/10.20849/ajsss.v4i4.694

\begin{abstract}
The objective of this report is to identify and review the implementation, use, maintenance, and extension of existing technology systems within the ABC (Australian Broadcasting Corporation) organization and establish success factors for enhancing their sustainability and flexibility to evolving user requirements and how data is transferred within the organizational system. It will go through a revised Enterprise architecture strategy that has been adapted to the fast paced technologically enabled changing market.

Currently, the $\mathrm{ABC}$ is experiencing a growth in viewers/customers due to new streams of media, public interest, generational targeting therefore and the widespread adoption of accessing news via social media. This EA (enterprise architecture) strategy will be implementing new technology through capital investment which will optimize the ABCs operational capabilities.

This report firstly analyzed the problem of $\mathrm{ABC}$ current situation which followed by coming up with an improved TOGAF approach, an implementing plan and an expected result in the end.
\end{abstract}

Keywords: Information system innovation, enterprise architecture, TOGAF approach implement, analyzing of ABC current situation

\section{Introduction}

The ABC (Australian Broadcasting Corporation) has been experiencing a new wave of viewership within the Australian community. This new wave can be predominantly categorized as the new generation of Australian's who value high quality user experience as a requisite for interacting with any form of media. As technology trends shift the $\mathrm{ABC}$ has been able to adapt to this new market through the implementation of mobile applications, web applications, and new specific channels on the Television network.

Thus, the problem currently being faced by the ABC is how information is shared and stored throughout the whole organization. The volume of information to date has been managed using separate data stores, with multiple communication links throughout the enterprise. This has resulted in multiple hard coded application programming interfaces (APIs) implemented over time to connect business processes together. This design is the result of continuous soloing iterations of business unit processes improvements without an overall Enterprise Architecture view of the system.

Additionally, with growth on the radar for the $\mathrm{ABC}$ and projections showing over the next $2-5$ years an exponential need to manage data and maintain performance in alignment with the $\mathrm{ABCs}$ vision and the $\mathrm{ABC} A \mathrm{Act}$ Part A to:

'to provide high quality content and services that will ensure $A B C$ is valued by the community'

And

'to provide within Australia innovative and comprehensive broadcasting services of a high standard as part of the Australian broadcasting system consisting of national, commercial and community sectors and, without limiting the generality of the foregoing...'

The approach towards the issues currently being faced by the $\mathrm{ABC}$ is to follow a modified TOGAF* approach, a proven EA methodology and framework used internationally to improve business efficiency. This approach has 
been modified to suit the specific needs of the $\mathrm{ABC}$, a state owned corporation (SOC) with an appropriate level of governance systems implemented to match the organizations obligations and risk profiling matrix.

(TOGAF*: The TOGAF standard provides a new thinking of enterprise architecture management for organizations to improve the efficiency of business. It means 'The Open Group Architecture Framework '; which is one of the most popular and reliable Enterprise Architecture standard in modern society. This approach helps staff avoid being stuck into proprietary methods, work more efficiently and effectively, and gain a greater return on investment. )

Figure 1 shows the general workflow for the TOGAF approach.

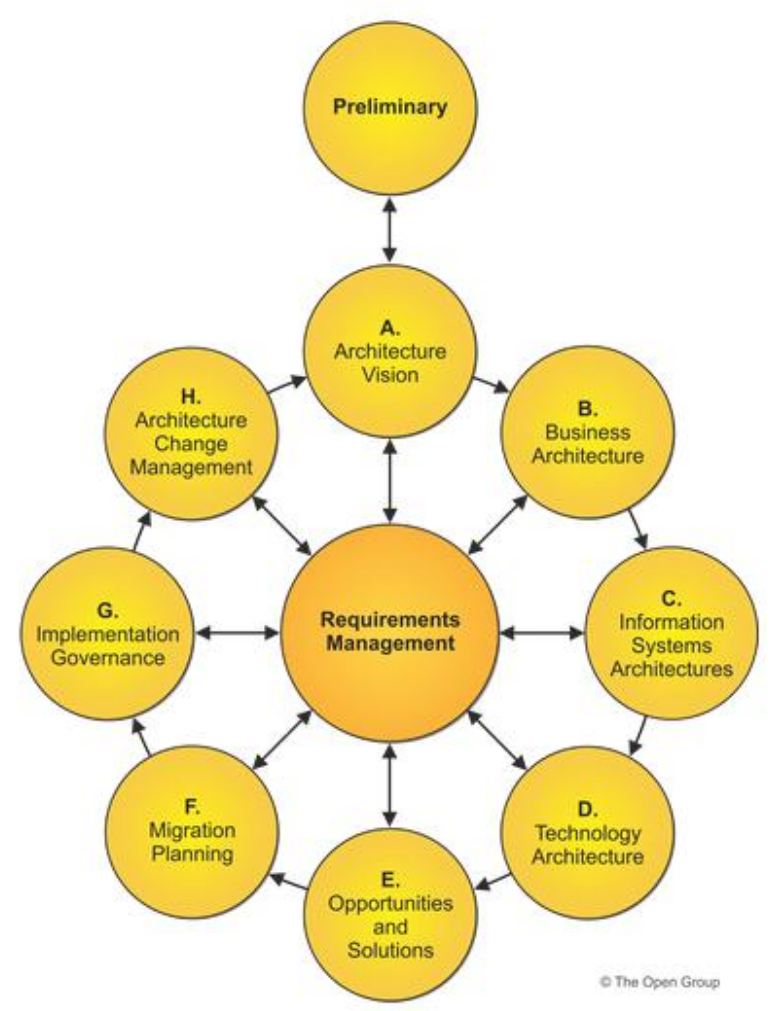

Figure 1. TOGAF methodology

During the implementation, we have gained details regarding the current state, investigated opportunities and solutions from an EA level to improve performance in alignment with the $\mathrm{ABC}$ core business objectives, and a detailed roadmap and implementation plan to achieve the desired result.

This report presents a systematic approach at a conceptual level which offers solutions by way of technology, business, and customer management solutions.

\section{Proposed Solution}

The proposed solution has been developed in collaboration with key $\mathrm{ABC}$ stakeholders by first understanding the current state of operation in the ABC. The findings revealed opportunities to incorporate a centralized cloud content management system to streamline information links throughout the enterprise.

Additionally, an opportunities and solutions matrix decision making tool was used in collaboration with $\mathrm{ABC}$ department heads to understand the priorities of the organization. It was found that both customer engagement management and content management was a high priority for the $\mathrm{ABC}$ and hence our proposed solution aligns with these priorities. Table 1 below is an excerpt from the workshops conducted with the ABC. 
Table 1. Opportunities and solutions matrix tool excerpt

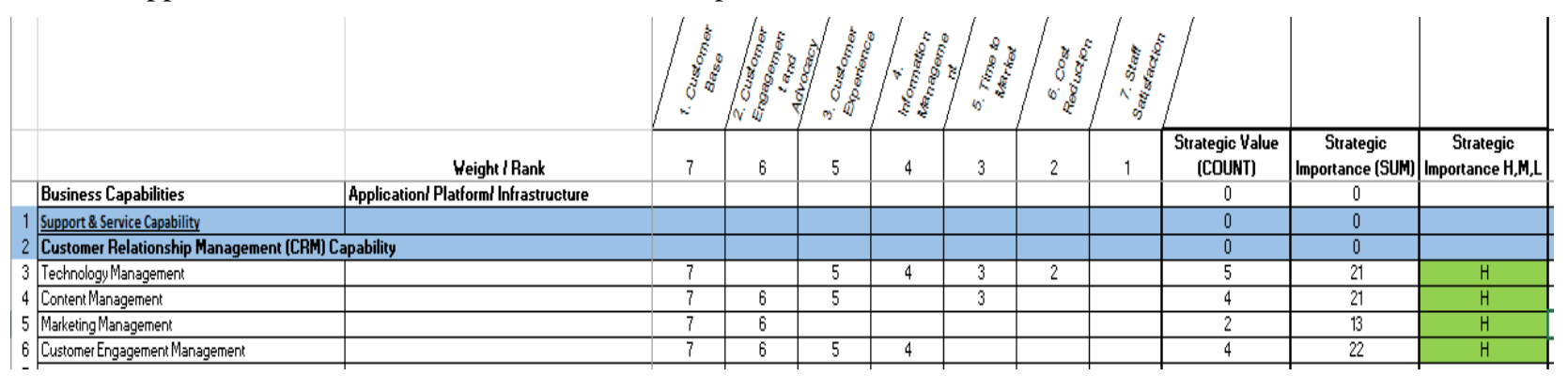

The proposed solution will act as an enabler for internal information streams to be optimized, minimize waste, and enhance business capability to ensure cost of operation does not increase and technical capability is maintained into the future. Figure 2 below is a conceptual application interaction model of how this may look.

In the 'Conceptual Application Interaction Model', the 'technology layer' will uplift the application layer and provide infrastructure and infrastructure service including database and content management; the 'application layer' has acted as a connecting layer, on the one hand, 'the application layer' produces different applications bases on the basic data and infrastructures, on the other hand, it supports different channels in business layer. The 'business layer' is the up layer of the Conceptual Application Interaction Model; it shows the application published in different channels and the analytics of customers' usage.

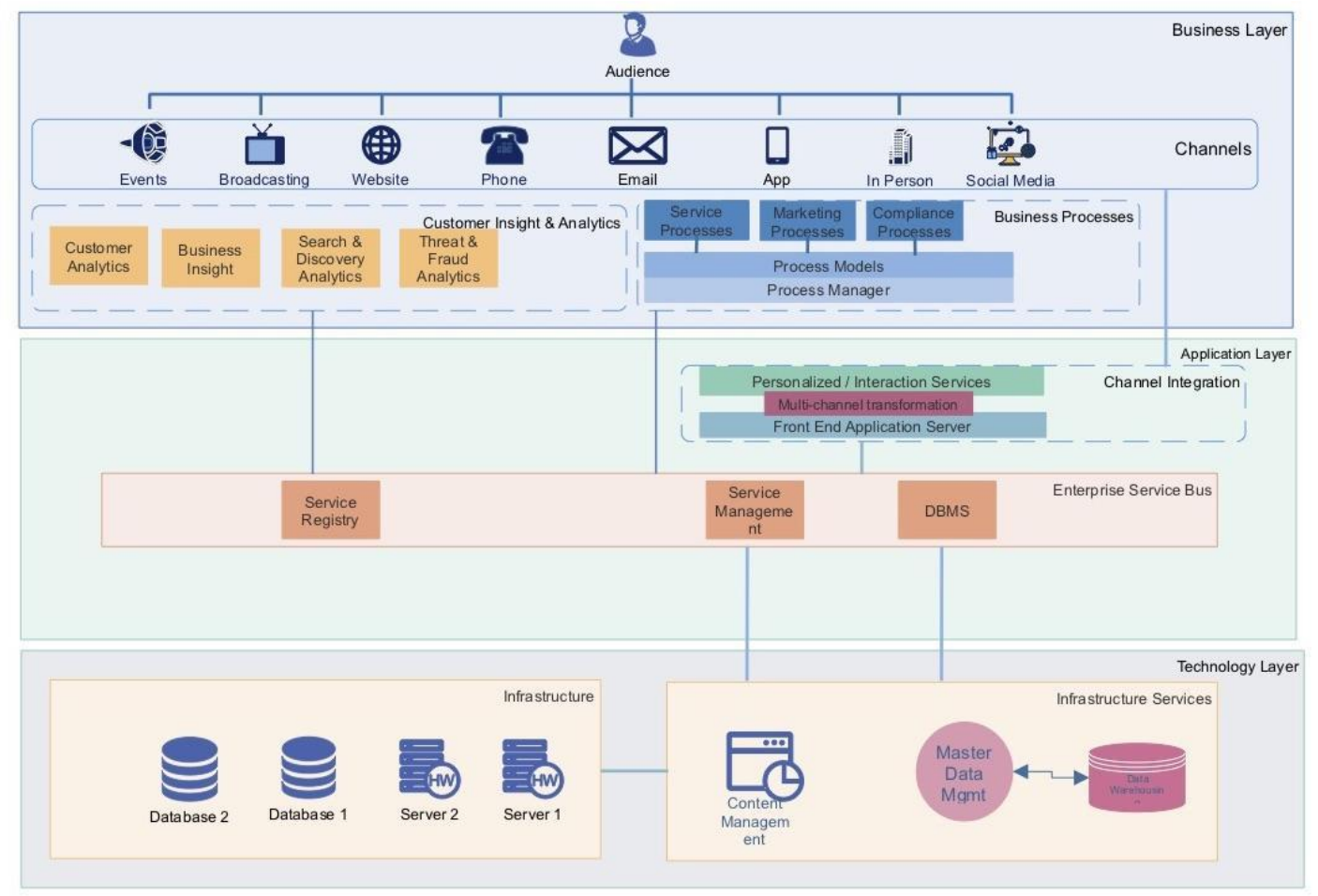

Figure 2. Conceptual application interaction model

The proposed solution will implement the following:

1. Improve cross-department collaboration by disseminating the narrow vertical management structure and the implementation of systems to enable leaders at all levels a platform to communicate and share information freely without obstruction or double-handling.

2. Performance criteria for departments to maintain accountability.

3. Empowering teams throughout the organization to produce meaningful outputs. 
In conclusion, this platform is well balanced and will provide both opportunities for improvement as well as challenges for both ongoing business considerations and implementation through change management. These opportunities and challenges are summarized below in Table 2 .

Table 2. Proposed solution: opportunities and challenges

\begin{tabular}{ll}
\hline Opportunities & Challenges \\
\hline $\begin{array}{l}\text { Improve customer data quality through single } \\
\text { source, area of responsibility, and traceability } \\
\text { within the organization }\end{array}$ & Upfront capital investment justification required \\
\hline $\begin{array}{l}\text { Improvement in community interaction through a } \\
\text { streamlined workflow }\end{array}$ & $\begin{array}{l}\text { Project Risk - Requires intricate planning in migration } \\
\text { of systems and data }\end{array}$ \\
\hline $\begin{array}{l}\text { Optimized marketing campaigns through data } \\
\text { analytics and end-to-end management in a single } \\
\text { location }\end{array}$ & $\begin{array}{l}\text { Organizational cultural resistance to changing legacy } \\
\text { workflows }\end{array}$ \\
\hline $\begin{array}{l}\text { Reduced time processing and vetting data within } \\
\text { the organization }\end{array}$ & $\begin{array}{l}\text { Additional hardware required to both operate and to } \\
\text { implement risk averse migration planning (parallel } \\
\text { systems if required) }\end{array}$ \\
\hline $\begin{array}{l}\text { Scalable as the organization grows over time } \\
\text { Outsourcing of risk and technical support }\end{array}$ & $\begin{array}{l}\text { Onaining and development programs will be required as } \\
\text { well as ongoing maintenance of skills. }\end{array}$ \\
\hline \begin{tabular}{l} 
services for subscription based services. \\
\hline
\end{tabular}
\end{tabular}

\section{Key Findings and Proposed Deliverables}

\subsection{Business Motivation Model (BMM)}

The BMM is the starting point of our investigation;

Our lens into business improvement is linked to the key motivations of the organization to optimize both the means and the ends for achieving the core objectives for the $\mathrm{ABC}$ to align with;

- public expectations; by being a trusted content provider who using the latest technologies/platforms, and

- shareholder expectations; innovative and comprehensive broadcasting services of a high standard.

The $\mathrm{ABC}$ core objectives align closely with public perception and reputation as being a trusted and reliable source of information and entertaining regarding both news and culture. As the viewership increases so does the demand on the organization to be customer focused and agile in the way they operate. Funding for the ABC in recent times has been reduced as the Australian budget has reallocated funding to other areas of the economy. This is expected to remain the same into the future so it is critical that public perception is maintained so that voters will see value in public funding being allocated to the $\mathrm{ABC}$.

This puts the $\mathrm{ABC}$ in a unique position with an opportunity. To increase their public perception and presence so that funding is maintained, as well as an opportunity to optimize business operation resulting in less funding requirements to achieve the core objectives listed above. The BMM below (figure 3) has been developed and agreed in collaboration with $\mathrm{ABC}$ department heads.

In figure 3, vision, goals and objectives have been separated: 'vision' shows the 'One of the main strategic decision of the organization', and it helps $\mathrm{ABC}$ clear what the company want to become in the future: providing high quality content and services that will ensure $\mathrm{ABC}$ is valued by the modern society. As for 'goals', it tends to be longer term and gives more attention on qualitatively instead of quantitatively. For $A B C$, we aim to set a working environment full of respect, integrity and embrace innovation in the long term. Pertaining to 
'objectives', it provides the foundation for measuring whether current progress is being made towards the goal.
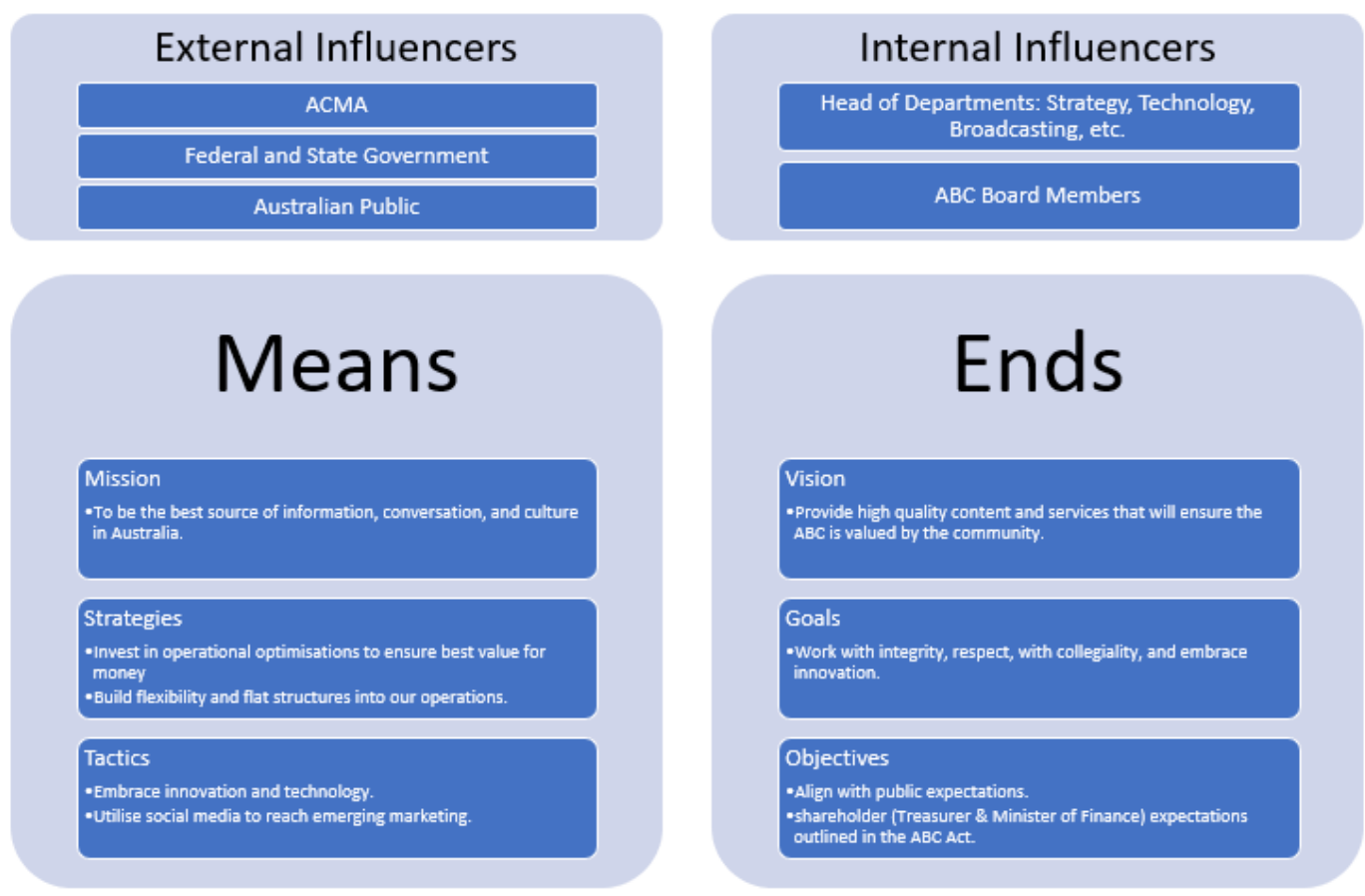

Figure 3. Business motivation model

\subsection{Business Capability Mapping}

The business process stream and capability mapping was done to understand the core flow of the organization as shown in figure 4 below. This process allowed the team to understand where each business division sits in relation to the $\mathrm{ABC}$ meeting its core objectives.

The maturity of each business unit in relation to effectively meeting their objectives was also conducted. Besides, this highlighted that there is a maturity breakdown regarding objective 3: present data/news in an interactive media form.

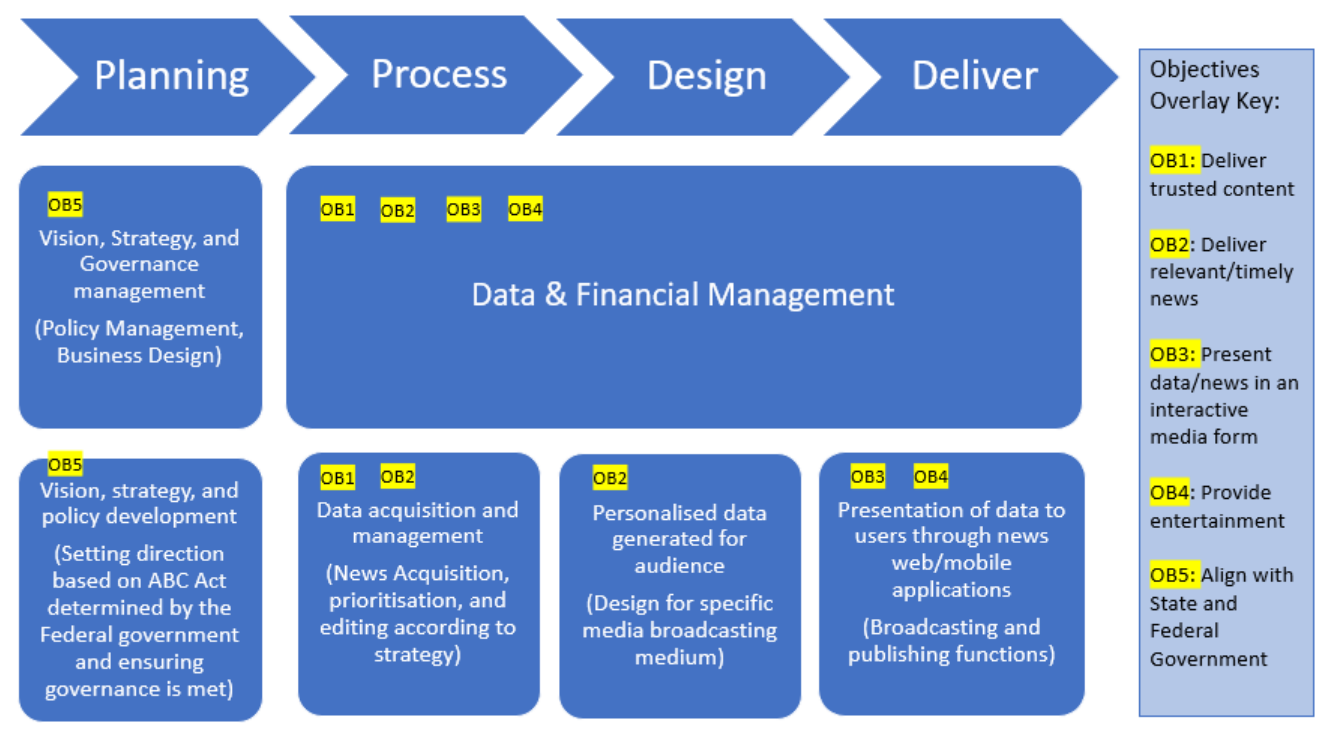

Figure 4. Business capability map with objectives overlay 


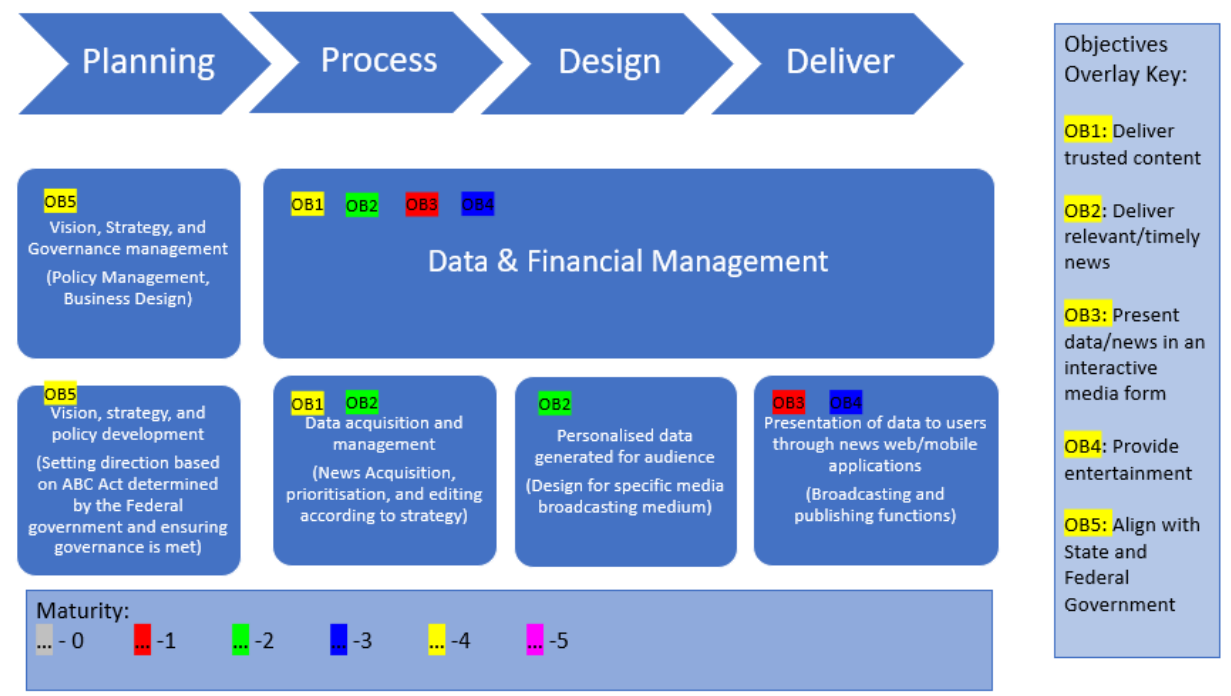

Figure 5. Business capability map with business maturity overlay

\subsection{Portfolio Model - Information Architecture}

The portfolio model describes which business concept the ABC should store data about, which business concept the $\mathrm{ABC}$ should keep track. Each business concept represent a group of information that is used to support the strategic direction and delivery of services.

According to the project is aiming to improve the customer experience and increase the efficiency of data information exchange. In order to attract more audiences and customer form new generation. ABC is targeting at the new broadcasting channels (e.g. a new mobile application) and provide unique content to different viewers in refers to their preference. The models in figures 6 and 7 present the current and future architecture of portfolios respectively. Figure 7 provides a solution of information integration by implementing a CRM system. The CRM system links the data from the perspectives of 'User', 'Stakeholder', 'Marketing' and 'Content' together to provide a customer based and more personalized service to the audience. In figure 7, the data from new application has also been considered as one of the components for the marketing sector, by acquiring these information $\mathrm{ABC}$ would be able to measure whether the new applications are successful, and what would be the improvement to attract more users. The change from an architectural point of view is that the implementation of CRM will effectively link data together for separate business units to utilize.

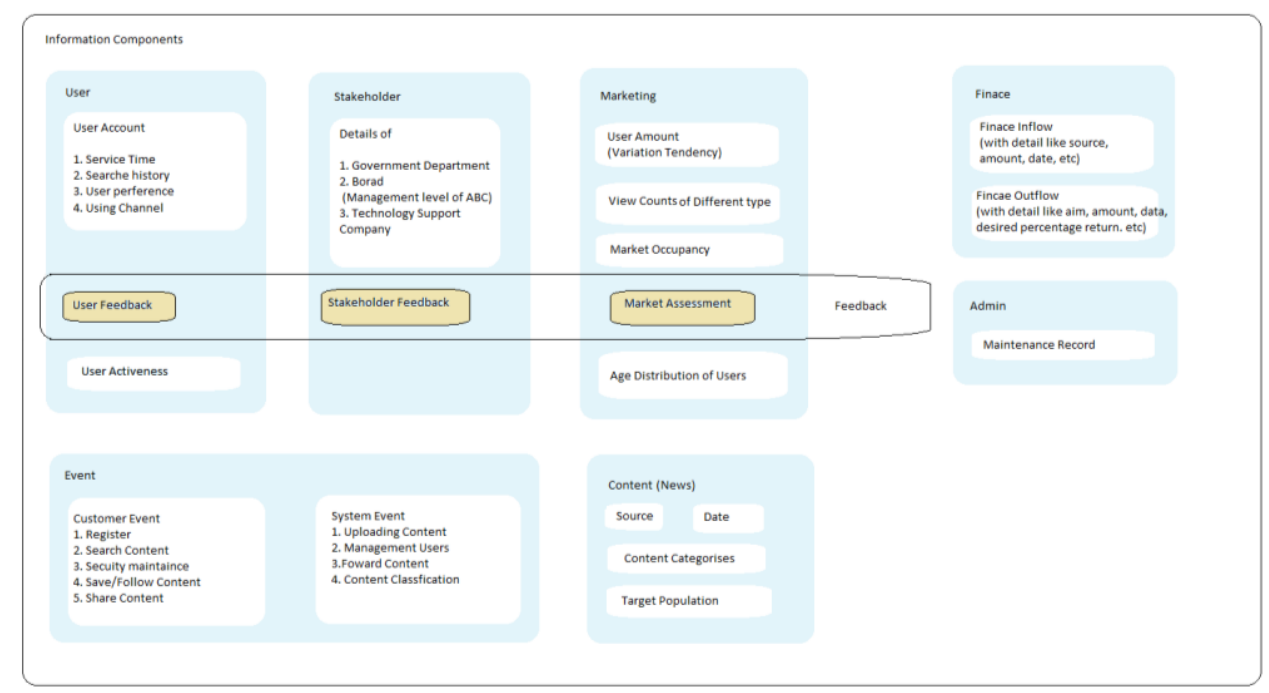

Figure 6. Information portfolio model of current stage 


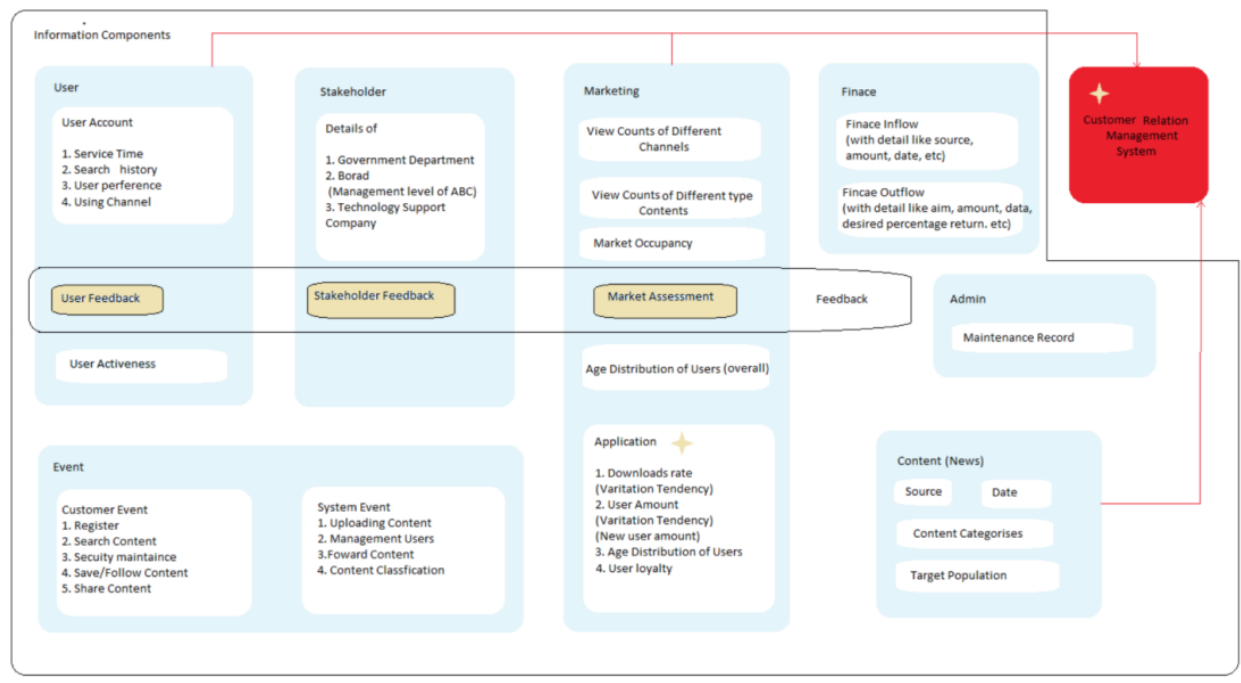

Figure 7. Information portfolio model of future stage

\subsection{Relational Modelling - Information Architecture}

The models below are an example of how the implementation of a CRM will optimize the flow of data throughout the digital mediums current in use and being developed for future use. Figure 8 shows how data from both web and mobile applications interact with the ABC. It shows that the current system uses multiple communication lines to retrieve specific data. For example; if data about users and news is required for business operations. The data is stored in separate business systems, i.e. the user data within the digital operations division system, and the news data is stored inside delivery and broadcasting division system.

Figure 9 depicts how a CRM system can 'centralize' all recorded data and hence it is easily accessed by anyone in the organization in relation to any other specific data that may be needed for business operations. From figure 8 to figure 9, the information flow in the $\mathrm{ABC}$ should be more effective and less redundancy in the future.

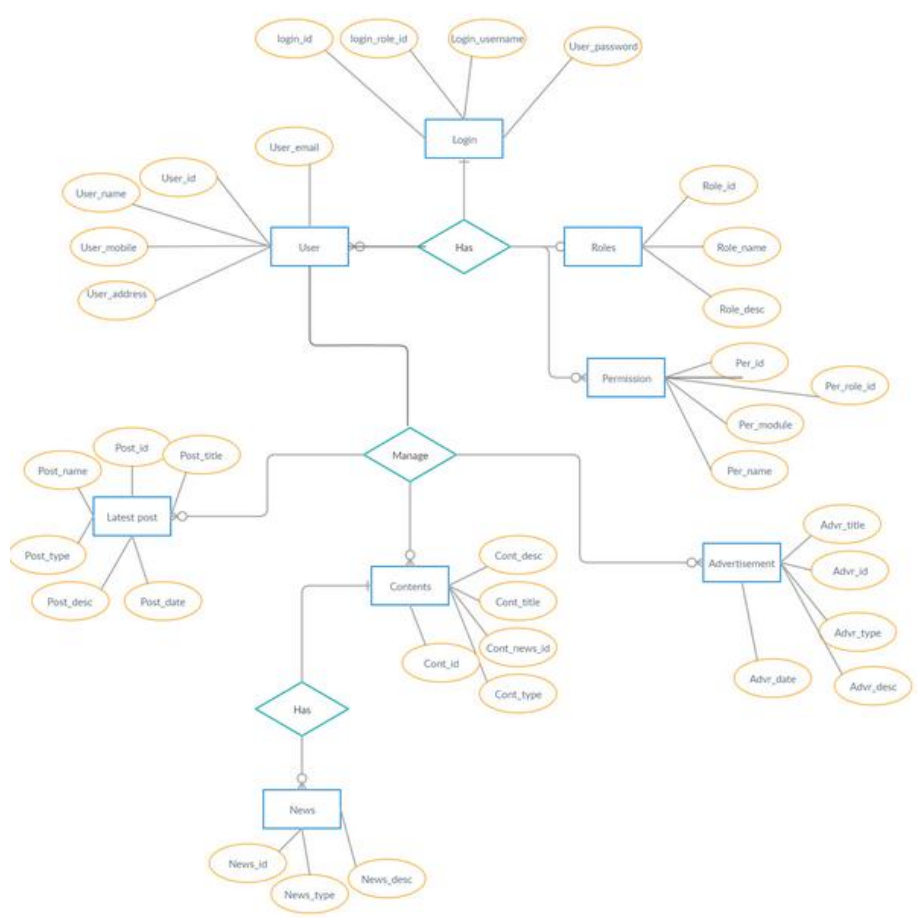

Figure 8. Current relational model ABC 


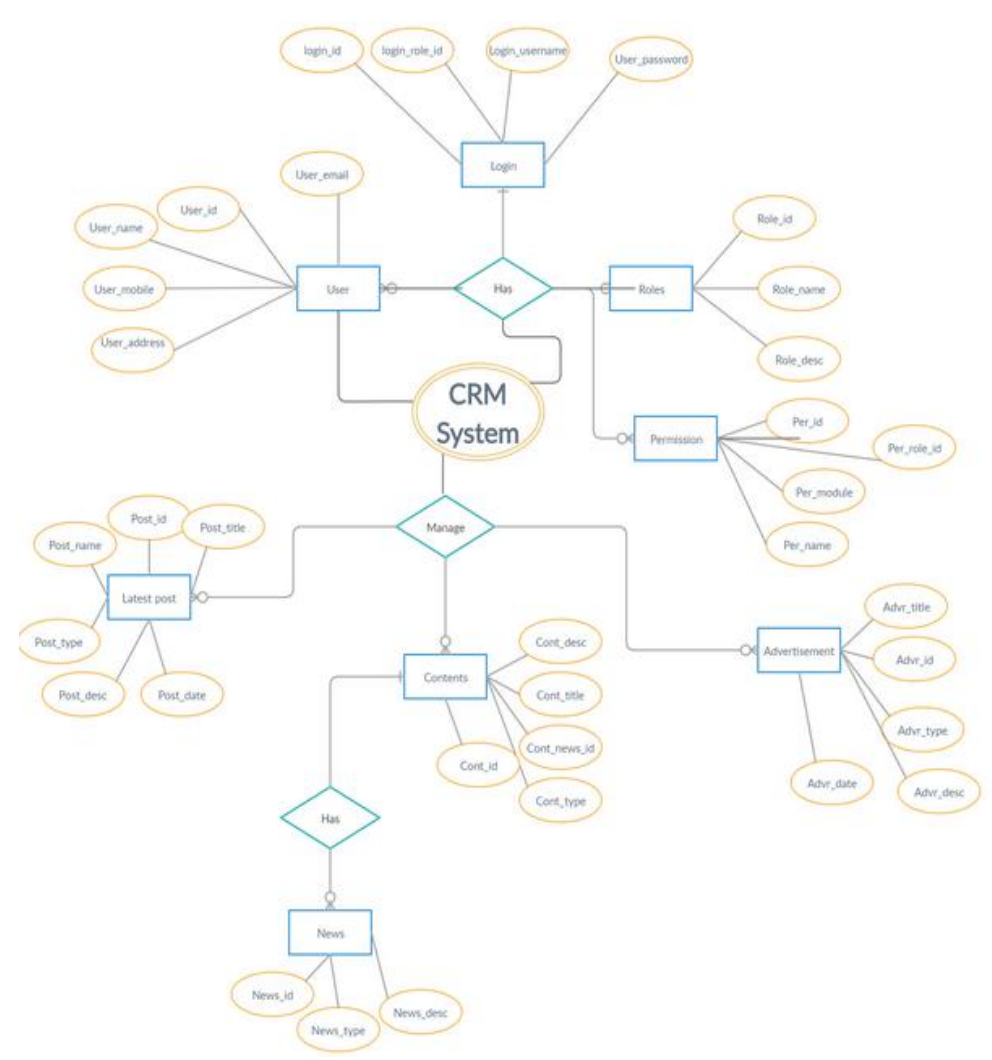

Figure 9. Proposed conceptual relational model ABC

\subsection{Information Exchange - Information Architecture}

A more detailed looks at how the proposed CRM solution may interact with existing ABC information streams can be seen in figure 10. The diagram (figure10) shows a circular economy of information flows to and from the CRM as the focal point. This system will handle data storage routing from multiple places such as customer/viewer data, financial data, strategy, and news content information.

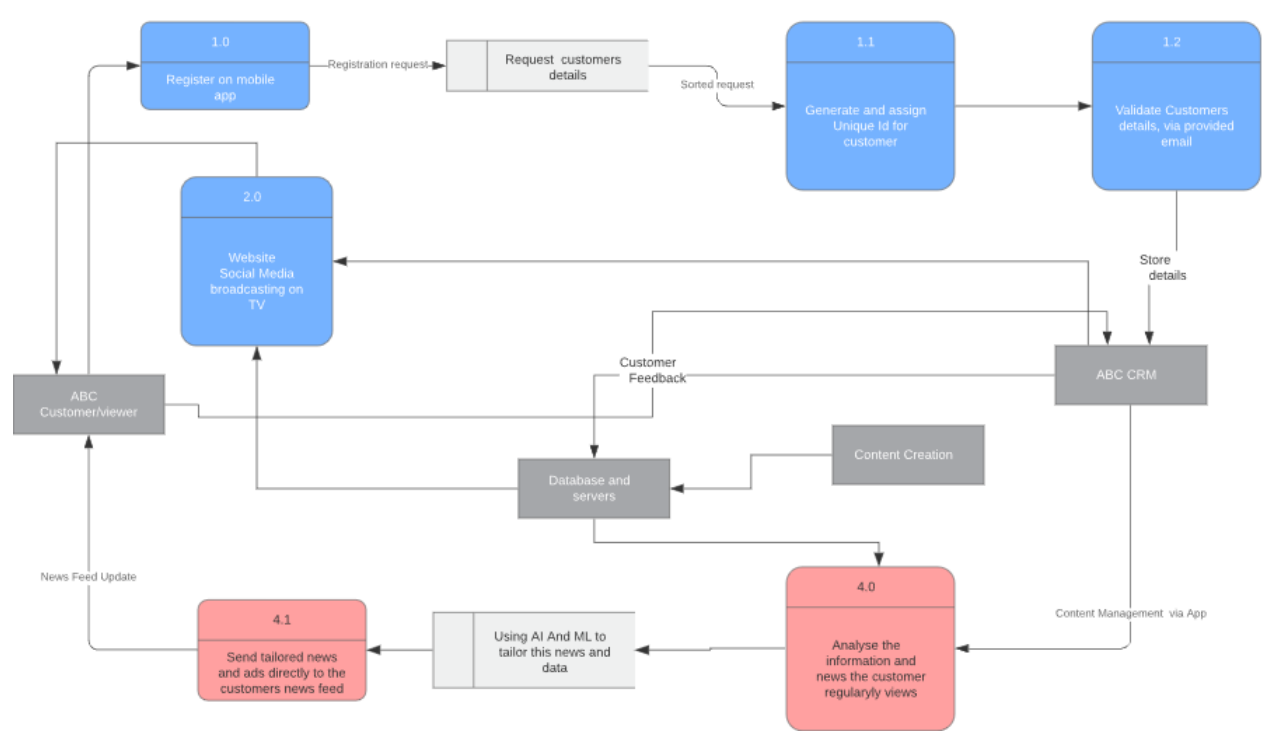

Figure 10. CRM interaction with various $\mathrm{ABC}$ media streams 


\section{Implementation Planning}

A number of projects have been identified and prioritized in Table 3 and Figure 11 respectively.

A combination of systems updates, software, and hardware projects will be required to ensure a successful outcome is achieved.

Additionally, the project team involved in the strategic planning, the Architecture team (Figure 12)

Table 3. Proposed implementation projects

\begin{tabular}{|c|c|c|}
\hline $\begin{array}{l}\text { Priority/Ph } \\
\text { ase }\end{array}$ & Project Name & Project Detail \\
\hline 1 & $\begin{array}{l}\text { Architecture and detailed } \\
\text { plans approvals }\end{array}$ & $\begin{array}{ll}\text { - } & \text { Conduct detailed requirements analysis } \\
\text { - } & \text { Finalize entire project details } \\
\text { - } & \text { Seek endorsement } \\
\text { - } & \text { Procurement strategy approval from } \mathrm{ABC} \text { board } \\
\text { - } & \text { [Hold Point] : Funding approval from ABC board }\end{array}$ \\
\hline $2 \mathrm{~A}$ & $\begin{array}{l}\text { Hardware Procurement and } \\
\text { Installation }\end{array}$ & $\begin{array}{l}\text { - } \quad \text { Set up contracts with service providers } \\
\text { - } \quad \text { Installation of hardware requirements }\end{array}$ \\
\hline $2 \mathrm{~B}$ & $\begin{array}{l}\text { CRM package selection and } \\
\text { requirements analysis }\end{array}$ & $\begin{array}{l}\text { - Match package requirements with business needs } \\
\text { - } \quad \text { [Hold Point] : Ensure service requirements are met and } \\
\text { gain endorsement from divisional heads }\end{array}$ \\
\hline $3 \mathrm{~A}$ & $\begin{array}{l}\text { Hardware, software } \\
\text { integration and temporary } \\
\text { operating modes setup }\end{array}$ & $\begin{array}{l}\text { - Integrate new infrastructure with existing operational } \\
\text { requirements } \\
\text { - } \quad \text { Set up operating modes in parallel with existing system }\end{array}$ \\
\hline $3 \mathrm{~B}$ & $\begin{array}{l}\text { Process checking and } \\
\text { migration (one by one } \\
\text { divisional switching to the } \\
\text { new system) }\end{array}$ & $\begin{array}{l}\text { - Process and quality checking of functionality against } \\
\text { user/business requirements } \\
\text { - [Hold Point] : Approval of functions against project } \\
\text { objectives by the governance team } \\
\text { - Migration of functions over to new system }\end{array}$ \\
\hline $3 \mathrm{C}$ & $\begin{array}{l}\text { Usability testing, document } \\
\text { handover, and user training } \\
\text { rollout }\end{array}$ & $\begin{array}{ll}\text { - } & \text { User testing and training rollout } \\
\text { - } & \text { Modifications based on user feedback } \\
\text { - } & \text { Documentation handover }\end{array}$ \\
\hline 4 & $\begin{array}{l}\text { Final migration, system } \\
\text { monitoring, and defect } \\
\text { rectification }\end{array}$ & $\begin{array}{ll}\text { - } & \text { Final acceptance testing } \\
\text { - } & \text { Ongoing monitoring and system support } \\
\text { - } & \text { Defect rectification }\end{array}$ \\
\hline
\end{tabular}




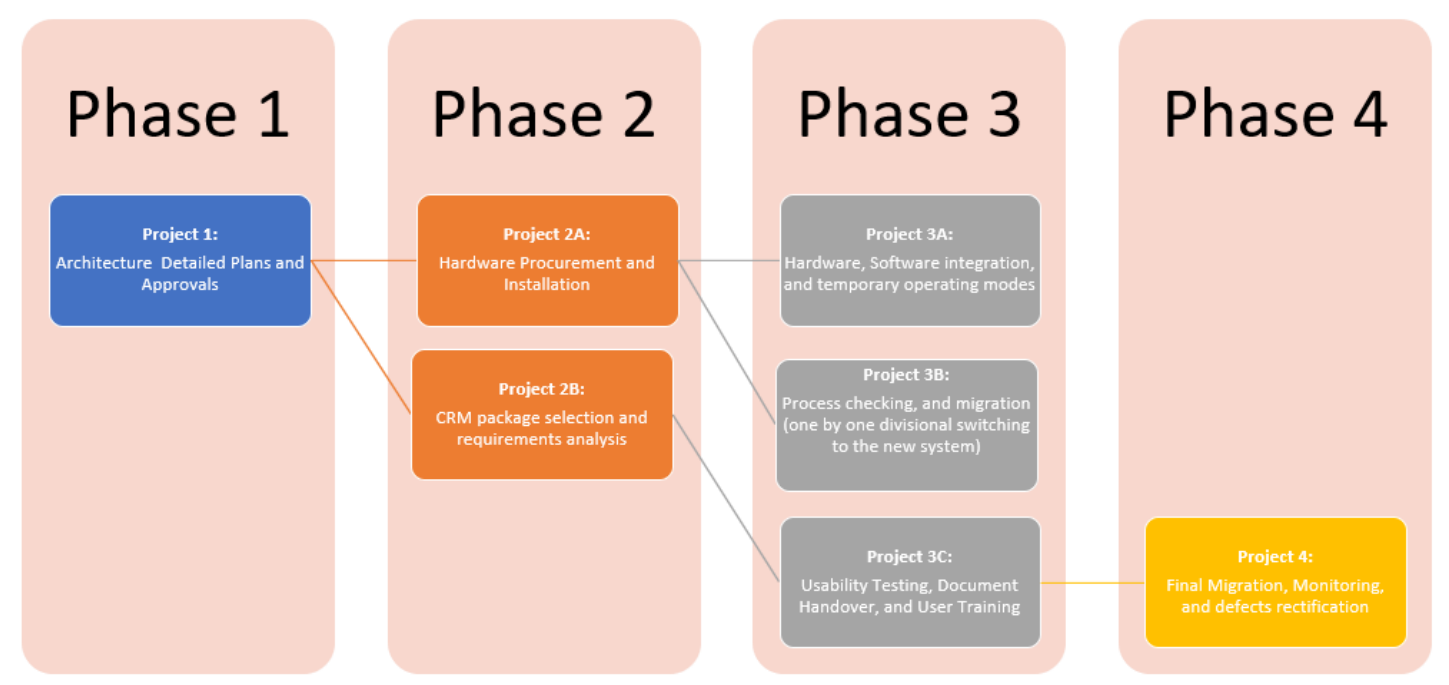

Figure 11. Project roadmap

\section{Governance Structures and Processes}

The project will adhere to a formal governance structure developed in collaboration with the ABC management. The proposed structure is detailed below in Figure 12.

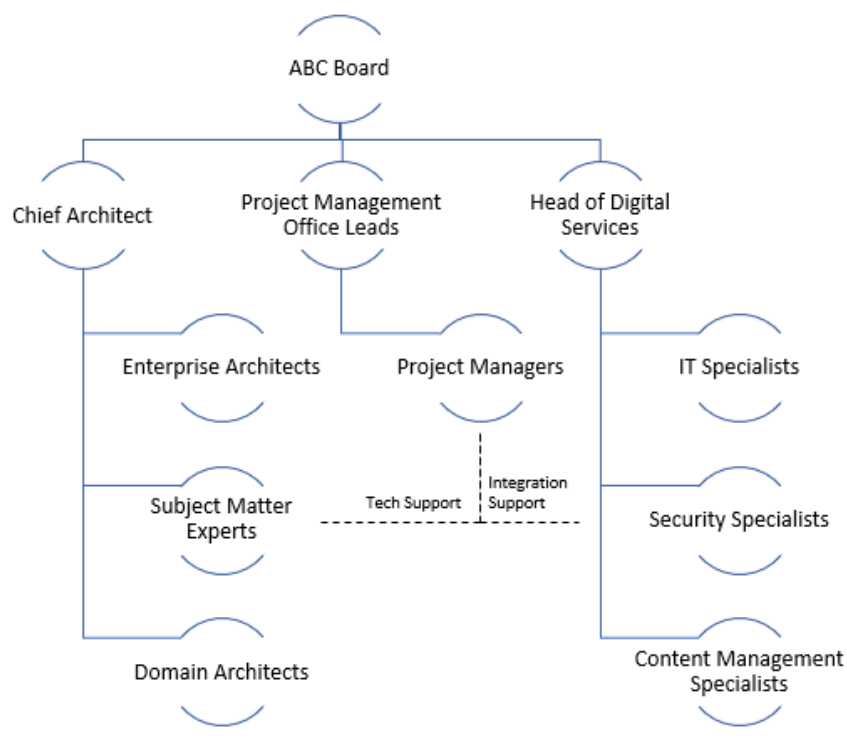

Figure 12. Governance structure

Our proposed governance structure is summarized below;

\section{Phase 1}

- Enterprise Architecture team:

- Develop and seek approval of EA plans through ABC Board

- Develop and allocate timeframes and budget for project management team for delivery

- Project Management Office:

- Agree on scope, time, and budget 
- Allocate resources for project delivery

- Head of Digital Services:

- Agree on scope and technical deliverables

- Agree on implementation/migration planning

\section{Phase 2}

- Enterprise Architecture team:

- Ensure hold points (table 3) are maintained and documented

- Project Management Office:

- Maintain project timeframes, scope, and budget

- Implementation of Project 2A and 2B

- Head of Digital Services:

- Technical support during project delivery

\section{Phase 3}

- Enterprise Architecture team:

- Ensure hold points (table 3) are maintained and documented

- Project Management Office:

- Maintain project timeframes, scope, and budget

- Implementation of Project 3A, 3B, and 3C

- Maintain change register and variations

- Head of Digital Services:

- Technical support during project delivery

- Facilitate training and handover documentation

- Final acceptance testing

\section{Phase 4}

- Enterprise Architecture team:

- Final hold points to check all project objectives are met with the delivered scope

- Project Management Office:

- Finalize handover documentation

- Provide technical support during monitoring phase

- Address defects/issues which arise

- Head of Digital Services:

- Acceptance of handover documentation

- Acceptance of final product

- Maintain training sessions

- Ensure all security protocols are in place

We aimed to set several management positions in our team to manage the resource, control each phase and keep track with the upgrade processes:

The management positions includes: The Chief Architect; Subject Matter Experts; Enterprise Architects; Domain Architects

\section{Conclusion}

In summary, in order to provide innovative and latest technology platform to customers and maintain their trust, new projects and changes have been introduced. A new CRM (Customer Relationship Management) system utilized to build stronger relationships with audiences and receive early customer feedback. By creating new mobile and web application, new platform channel has been introduced to target mobile device users' viewers 
and address the growth.

Different project has been identified to carry out this mission. Each project will be implemented in different phases to allow early customer feedback and a smooth transaction to new platform. These project has been designed to improve customer experience, reduce costs and provide more centralized data sharing system for better business management. The end vision is having outstanding customer engagement management and business management to better serve the emerging demand.

The new system is designed to be scalable and flexible for future growth and unavoidable changes.

\section{References}

Alex, G.. (n.d.). Improving Government Performance through Enterprise-Focused Development. Journal of Enterprise Architecture. Retrieved June 6, 2019, from https://online.uts.edu.au/bbcswebdav/pid-3653149-dt-content-rid-51138722_1/courses/32570-41003-2019SPRING-CITY-01/2018_EA\%20books\%20Review.pdf?VxJw3wfC56=1575621371\&6F691BFFBD=42126 3092\&3cCnGYSz89=v\%2Fd49pnjh9izkTbx0oSDXS87iObl5sRK0WM7tEvqYgk\%3D

Brooks, T. (2008). Which Comes First, Strategy or Architecture?. Journal of Enterprise Architecture. Retrieved June $8, \quad 2019, \quad$ from https://online.uts.edu.au/bbcswebdav/pid-3653149-dt-content-rid-51138722_1/courses/32570-41003-2019SPRING-CITY-01/2018_EA\%20books\%20Review.pdf?VxJw3wfC56=1575621371\&6F691BFFBD=42126 3092\&3cCnGYSz89=v\%2Fd49pnjh9izkTbx0oSDXS87iObl5sRK0WM7tEvqYgk\%3D

Business Model of Banking companies. (2019). Retrieved July 19, 2019, from https://online.uts.edu.au/bbcswebdav/pid-3653166-dt-content-rid-51138764_1/courses/32570-41003-2019SPRING-CITY-01/Banking-Business-Model\%20Example.png

Gill, A. Q. (2015). Adaptive Cloud Enterprise Architecture. World Scientific Publishing

John, A. Z. (2011). Architecture is Architecture is Architecture. Retrieved August 18, 2019, from https://www.zachman.com/ea-articles-reference/52-architecture-is-architecture-is-architecture-by-john-a-za chman

Osvalds, G. (n.d.). The Enterprise Architecture Reference Cube. Journal of Enterprise Architecture. Retrieved June 6, 2019, from https://online.uts.edu.au/bbcswebdav/pid-3653149-dt-content-rid-51138722_1/courses/32570-41003-2019SPRING-CITY-01/2018_EA\%20books\%20Review.pdf?VxJw3wfC56=1575621371\&6F691BFFBD=42126 3092\&3cCnGYSz89=v\%2Fd49pnjh9izkTbx0oSDXS87iObl5sRK0WM7tEvqYgk\%3D

TOGAF® Certification: How to Get Started with Individual Certification. (2019). Retrieved May 18, 2019, from https://www.opengroup.org/certifications/togaf-individual-certification

\section{Copyrights}

Copyright for this article is retained by the author(s), with first publication rights granted to the journal.

This is an open-access article distributed under the terms and conditions of the Creative Commons Attribution license (http://creativecommons.org/licenses/by/4.0/). 